\author{
V International Forum on Teacher Education
}

\title{
Axiological Characteristics of Digitalized Education
}

\author{
Oxana V. Gordienko*(a), Anastasiya A. Sokolova (b), Anastasiya A. Simonova (c) \\ (a), (b), (c) Moscow Pedagogical State University, Moscow, Russia
}

\begin{abstract}
The relevance of the problem of digital transformation of education is mainly connected with digital technologies and their focus on learning, however educational and development potential of this process and its axiological component are frequently ignored. If cultural and national values are continued to be disregarded, there is a risk of replacing them with a surrogate of a cultivated by the government model of a citizen. This article draws attention to the necessity of a purposeful formation of value beliefs and a national code in the process of digital transformation of the education system, of identifying and presenting the risks of this process, as well as means to solve possible problems. The following methods were used: analysis of academic sources on the issue, method of independent evaluations, monitoring, modelling. The main approach of the study is axiological.
\end{abstract}

Keywords: digital transformation, axiological component of education, national identity, meaningful content of education, digitization of education.

(C) 2019 Oxana V. Gordienko, Anastasiya A. Sokolova, Anastasiya A. Simonova

This is an open access article distributed under the terms of the Creative Commons Attribution License (CC BY 4.0), which permits unrestricted use, distribution, and reproduction in any medium, provided the original author and source are credited.

Published by Kazan Federal University and peer-reviewed under responsibility of IFTE-2019 (V International Forum on Teacher Education) 


\section{Introduction}

1.1. Study relevance. Due to the global trend of digitalization, which influences all spheres of human activity (digital ID - digital passports and other documents, e-Residency - e-citizenship, Data Embassy - digital embassy, e-Government - e-government, e-learning - e-learning, digital medicine digital healthcare, digital economy, etc.), it is necessary to train highly qualified teachers who not only know how to use modern technologies, but also are capable of creating future technologies in everyday professional activities. Thus, it is necessary to develop professional skills (Hard skills) and personal qualities (Soft skills), which include cognitive, communicative, creative skills, as well as cooperation, emotional intelligence, decision-making skills, managerial skills, etc. (Cohen, Manion, \& Morrison, 2018). The leading role in this process belongs to education, which should both adapt future educators to the needs of the system and modify modern digital technologies that follow integration of cognitive practices. This process should be based on humanistic ideals, universal and national values implemented into every new component in the general education system (Gordienko, 2017).

Technologization and digitalization should not be approached as a goal in themselves; digital transformation processes should be based on universal human values and preserve the unique sociocultural code of a nation. This idea is particularly significant for pedagogical education, since a teacher must not only be a bearer of basic values and cultural meanings, but also know means and methods of teaching younger generation such key values as freedom, responsibility, equality, development, cognition and security in the digital era (Lubkov). Teaching culture, one of the preferable ways of introducing these values, is also "a frame for describing many processes related to education" (Popov \& Ermakov, 2019), that is, there is a certain set of knowledge that any representative of the national community should become acquainted with. Thus, axiological characteristics are foundation of any transformational process of the educational system, including the digital one. In this regard, development of philosophical and methodological foundations of digitalization based on axiological, anthropocentric and epistemological principles becomes one of the urgent problems.

The transition to digital education is associated not only with the process of converting analog technologies to digital, but also with complex changes of infrastructural, managerial, behavioral, cultural nature, as well as changes in the communication paradigm. The basis of any conscious and purposeful transformation should be, on the first place, a person and a system of values, which is especially important for the education system. Digital technology is a tool developed for a specific purpose based on values and has its own area of application, which must be researched and defined in accordance with the its characteristics, its axiological and anthropocentric potential.

Digitalization, like any process, has three main characteristics: meaningful, organizational and technological. And if technological and organizational components of this process are studied both by foreign (Bailey, Vaduganathan, Henry, Laverdiere, \& Puglese, 2018), and by Russian researchers (Verbitskiy, 2016; Kyazimov, 2016), then its content, which is the most closely related to the axiological aspect, takes a second place, since knowledge paradigm is considered obsolete. However, it is necessary to understand that digitalization is just a form, it cannot exist without content. There is a fundamental knowledge that does not become obsolete over the centuries; methodological knowledge is also present, but now it is more susceptible to change and is associated with the existing paradigm of science and education at a particular time. Such knowledge is less stable, but it is necessary for the development of the world in a certain period of time; technological knowledge is most susceptible to changes, which should follow the development of science and technology. Although the pyramid of knowledge is not constant - its 
foundation is stable, but the top can change, completely abandoning the whole scheme and replacing knowledge solely with skills leads to catastrophic consequences. Skills cannot spur the development of cognitive and creative abilities; skills are not aimed at educating creators, but at formation of consumers. Only the aforementioned pyramid allows building a hierarchy of knowledge that has axiological foundations of each of the elements and keeps different scientific meanings on the axis of anthropocentricity. Behind any form of knowledge stands a holistic concept of culture. Leonardo Da Vinci would not have created his masterpieces without the Renaissance epoch, which determined many of his discoveries and ideas. Only mastering the entire complex system of cultural codes (phenomena and modes of activity that must be internalized by students in the process of mastering sociocultural meanings), their axiological features and creative ideas can draw a fine line between a man and a machine (robot).

It is necessary to understand that in the modern world, digital technologies should be primarily based on human values, which are designed to integrate technology into reality, and not vice versa, when digitalization is put on the first place to the neglect of humanity. And if digital technologies are not based on human values, human education will stop and the programming of neural networks will begin.

1.2. Modern tendencies. Modern students, according to a number of researchers (Howe \& Strauss, 2008; Roskams, 2015; Verbitskiy, 2016; Kyazimov, 2016), are representatives of the digital generation; therefore, such digital technologies are close and understandable to them as the Internet of Things (Internet of Things - IoT: automatic identification tools (bar codes, Data Matrix, QR codes, etc.), data transfer); robotics, production technology and 3D printing; online learning, virtual and augmented reality, artificial intelligence, voice assistants (Alice, Siri, Alpha Go, Google Assistant, Cortana, etc.); searching for a digital footprint in information environments, social media, geolocation, audio and video recordings, etc.), etc. These technologies are also starting to be introduced into education, but using them without understanding their positive and negative aspects can lead to fragmentation, narrow-mindedness, which inevitably leads to one-sided perception of the world, change in the linguistic world-image. Thus, the digital generation speaks another language, the language of geeks, uses ubiquitous slang built on Anglicism, for example, "trash" instead of "nightmare", "trolling" instead of "mocking", "upgrade" instead of "update", "heyt" instead of "to hate", "agritsya" instead of "angry", "chilit"” instead of "rest", etc. as well as abbreviations, for example, D8 from "Data" - date, LOL from "Laughing out loud" - laugh out loud, IMHO from "In my humble opinion" - in my opinion, etc. In a certain way this is popularized by adults who widely use foreign words: "curriculum" instead of "learning content", "follower" instead of "subscriber", "stakeholder" instead of "interested", "cashback" instead of "money back", "Message" instead of "message", "timing" instead of "time", etc.

Use of borrowed words is considered a sign of intelligence and erudition; however it also causes a change both in language culture, and in the language picture of the world. Thus, modern schoolchildren and students practically do not use based on the national mentality phraseologisms, proverbs and sayings in their speech, they use memes. Modern youth does not understand the meaning of many sayings, and a meme, being informational surrogate, changes established cultural codes. Memes are a part of video democracy which, as Epstein (2017, p. 556) notes, has power over mass consciousness. It is confirmed by the fact that, in many students' opinion, proverbs and sayings are anachronistic; wisdom in a changed world has lost its meaning, while memes are recognized as a source of experience.

One of possible solutions is to introduce to school and university courses best examples of the Russian language that would demonstrate the connection between the native language and culture. Introducing cultural heritage through language can be explained by a deep genetic connection between 
culture and language. Protodeacon Andrei Kuraev, Professor at the Moscow Theological Academy, believes that "a person looks at the world not with his eyes but with his own language" (Kuraev, 2000), therefore, when in the process of formation of a system of students' worldview it is necessary to familiarize them with the language as cultural wealth of the society which has been preserved and multiplied over the centuries. Students should understand that the Russian national language reflects aesthetic development of reality and culture. Ushinskiy (1974) defining the value of learning about the native language by studying the native culture wrote: "A child when learning the native language does not only learn separate sounds, he/she drinks spiritual power from the chest of the native word. It explains its nature to better than any naturalist; it acquaints him/her with the character of the people around him/her, with the society among which he/she lives, with the history and aspirations better than any historian; it introduces him/her into folk poetry better than any aesthetic; it gives philosophical beliefs better than any philosopher".

The goal of the pedagogical impact is to educate a person who is socially valuable and internally free, a spiritually developed person with his own standpoint and high moral grounds. Spiritual development is defined as a moral state of a person, manifested as a willingness to follow ideas of freedom, humanism, social justice, truth, goodness, beauty, desire to understand the secrets of meaning of life, and ability to prioritize high moral ideals over immediate needs and inclinations. The foundations of spiritual culture are laid in the language: the Russian national character, Russian life is expressed in the native language; for everything there was in it a designation corresponding to the spirit of the people, its "national element" (Gogol).

Complex (aesthetic, patriotic, moral) education of students is considered to be the most progressive. In the process of such upbringing, children develop the best national qualities; they realize responsibility for transmission of national values.

The next problem with the digitalization of education lies in the field of thinking. Unfortunately, integrity, completeness, depth, fundamentality and conceptuality are perceived by many young people as remnants of the past. Young people prefer slogans like "Learn English in three days!", "Become a genius in a week", etc., they believe that without much effort you can achieve success in any endeavor.

Digital technologies have already changed the ways of perception and thinking (Dzib-Goodin, 2012; Roskams, 2015), socialization and the system of values, and this is why further ignoring axiological aspect in education will lead to the loss of national identity and social and spiritual credentials of generations.

Freedom by the younger generation is perceived as a total absence of authority, which is facilitated by the ability to hide their true face in the virtual world behind their avatar (invented names, appearance, biographies, etc.), while responsibility for their actions on behalf of a fictional digital alter-ego is not fully comprehended, which leaves an imprint on the person in the real world, whose identity is less and less recognized as real, being replaced by the conventionally imaginary. Escapism leads to a social gap, forms social autism, which increases aggression (a person reacts inadequately when taken away from the illusory world he or she has created). The absence of moral values and attitudes associated with the ambivalence of freedom (one person's freedom is limited where it encroaches on the freedoms of others) which leads to selfishness and intolerance.

Thanks to a dense information field a change in the ways of perception and thinking happens to everyone, even adults. Chaotic information gathered from various sources on the Internet gives rise to chaotic thinking. It is highly dangerous for a child who is constantly connected to social networks, receives scattered and contradictory information, and finds difficult to follow the right values and guidelines. The 
child is not able to comprehend what is right and what is not, what is good and what is evil, for him the world is a tangle of contradictory ideas and thoughts, not a pyramid system with all the meanings correctly strung on a moral axis. The human brain is stressed because it constantly has to process information received in the form of a muddled set of unrelated and contradictory information flows. Information overload, information noise, adversely affects a person's ability to adequately analyze the situation and make informed decisions. In this case, the problem is not that computers will start to think like people, but that people may start thinking like computers. One of the ways to solve this problem is teaching different methods of analysis, harmonization of information flows, and differentiation of necessary and unnecessary information. The main criterion here is the value of information, which is able to protect the brain.

Another problem is related to the fact that thanks to digital technologies, social networks and computer games children feel omniscient, do not recognize authorities, are impatient and focus mainly on short-term goals, they are less communicative in reality, communications have become more technogenic in nature, but at the same time they develop rapidly, children very quickly realize volatility of the digital world, they develop a false impression that a person can also be quickly modified. This is how American child psychologist Sherry Postnik-Goodwin describes them: "They prefer text message to conversation. They communicate online - often with friends they have never met. They are rarely on the street, unless the parents organize their leisure time. They cannot imagine life without mobile phones. They have never seen a world without high technology or terrorism. They prefer computers to books and in everything they seek immediate results. They grew up in an era of economic depression, and all of them are expected to be successful. Most of them grow up very quickly, behaving much older than their years" (cited in Verbitskiy, 2016, p. 11). Communication through social networks leads to social and personal transformation, hence the change in communicative channels, which, on the one hand, multiplies quantitatively, but is narrowed in a qualitative sense. All these factors transforms the worldview and habits developed throughout generations, people begin to perceive and judge the world differently.

The process of learning is changing: modern students in are primarily focused on the result. They do not enjoy the process. They focus on the new material, ignoring the "repetition of the past". The environment created by high technology is an important tool for them. Traditional lecture is similar to "a silent movie" for viewers who are accustomed to sound. They perceive visual information better than any other generation. If learning takes too long, they either refuse to study the course material, or look for information somewhere else (Coats, 2007). In this case, the value of knowledge disappears.

All this, ultimately, leads to a change in value-semantic paradigm of society, a change in cultural meanings and images that transforms processes of identification and socialization.

Now the main requirement for socialization is the ability to communicate through instant messengers and social networks.

"I" ceases to exist, instead network multi-facets appear (multiplayer worlds and fandom communities) which stimulates integration processes decline in identification and personification. It gives rise to network narcissism - a person is constantly trying to leave his digital footprint everywhere: leaves comments on other people's blogs, shares photo and video materials on other people's sites.

The solution to the problem could be found by appealing to the value aspect. Even in cyberspace the common ground should be value. To develop the system of values the whole system of working for the benefit of society should be created.

If the teacher is eliminated, the technology will take his place. This is already happening, for example, in the social networks where children and adolescents join communities that contain dubious and 
often harmful information.

The main role in digitalization should belong to a teacher who by using digital tools and technologies is able to shape an individual, develop basic social skills, strengthen national identity and spiritual and moral foundations.

Digitalization in China, for example, has made great strides forward, but national identity and value of education as a cultural phenomenon have are still important for them.

The Chinese-Russian Forum "Problems and Prospects for the Development of Education in a Digital Society" was held in Moscow Pedagogical State University (MPGU) in October 2018. Cheng Hunguang, Director of the Department of International Exchanges and Cooperation of Beijing Pedagogical University, talked about monitoring the quality of basic education by the Ministry of Education of China. He said that in the system of Chinese education, there are six basic school subjects: Chinese, mathematics, science (which includes biology, chemistry, geography), as well as physical education and art and there is also "moral education". The monitoring conducted in China among the 4th and 8th grades showed that Chinese students have a high sense of national identity. Over $90 \%$ of schoolchildren pride themselves on being Chinese. $96.2 \%$ of fourth grade students and $97.9 \%$ of eighth grade students are full of confidence in the future of the country. Their career aspirations are diverse: becoming a scientist, a military man, a teacher and a doctor is the ideal choice for schoolchildren. They also believe that education has a value: 93.2\% of fourth-graders and $82.3 \%$ of eighth-graders think so. This example shows the possibility of a correlation between digitalization and educational aspect.

As Sarnoff notes, "We are too predisposed to see technological tools as scapegoats for the sins of those who wield them. Products of modern science are neither good nor bad in themselves. Their value is determined by the way they are used" (cited in McLuhan, 1994, p. 13), but McLuhan himself believes that the impact of technology on a person does not occur at the level of opinions or concepts, but changes the perception and the person as a whole. Most likely, both researchers are right, because, on the one hand, there always was a dualism of good and evil in the human world, one cannot be imagined without the other, and ability to make a choice in this eternal dispute is extremely valuable, it is always a man who always makes a decision based on importance and needs and his responsibility. It is neither positive nor negative. On the other hand, use of any new instrument leads to the need for its development and reflection, which, of course, affects the person. Thus, the digital transformation of education requires system of analysis and control from gnosiological, anthropological and axiological positions.

\section{Results}

In the digital age the role of teacher is still vital for the society. Moreover, the role of pedagogy which studies upbringing and education comes to the fore. The humanity has enormous experience in creating various educational development systems. Its pioneer was Jan Amos Komensky. All these systems were created due to social demand, in search for a new person. The answer of the XVII century to the demand of a more educated person able to work with complex mechanisms was a system of lessons. The system can average an individual on the one hand, on the other, gives opportunities to gifted children from underprivileged social classes to broaden their horizons. This system turned out to be so viable that it existed for four centuries, until it faced the problem of individualization of learning and loss of semantic content due to development of technical devices. Modern teachers face a very difficult problem - they have to incorporate digital technologies into the process without losing the meaningfulness of the content. All this proves that we are on the threshold of the emergence of a new branch of pedagogy, capable of 
becoming the main direction of development of this science, both in terms of the educational paradigm and in terms of methodology and methodology; and the philosophical foundation of new developments should be axiology, which is able to combine the best achievements that have developed over the centuries with new digital innovations without losing the human identity.

Lack of moral values and meanings leads to the loss of national identity, the loss of a cultural code and a gap in communication with the real world.

Of course, digital transformation affects all spheres of human activity and positive influences that computers and gadgets bring to life of modern society are undeniable, but it is crucial to study the problems of socialization and self-identification in the digital world, therefore digital axiology should become a tool of "soft power" in the hands of pedagogical educators and it should make a positive impact on the fragile minds of the younger generation.

We cannot predict in which world our descendants will live, but if values are put on the first place, then we can be sure that this world will be humane and anthropocentric.

\section{References}

Bailey, A., Vaduganathan, N., Henry, N., Laverdiere, R., \& Puglese, L. (2018) Making Digital Learning Work. Success Strategies from six leading Universities and Community Colleges. Retrieved from https://edplus.asu.edu/sites/default/files/BCG-Making-Digital-Learning-Work-Apr-2018\%20.pdf

Cohen, L., Manion, L., \& Morrison, K. (2018). Research Methods in Education (8th ed.). London: Routledge.

Coats, J. (2007). Generational Learning Styles. Retrieved from http://cdn2.hubspot.net/hub/119076/file305826149-pdf/Generational_Learning_Styles_Chapter_1.pdf

Dzib-Goodin, A. (2012). Online Or In Class: The Shifting Educational Paradigm. Retrieved from https://evolllution.com/revenue-streams/distance_online_learning/online-or-in-class-the-shiftingeducational-paradigm/

Epstein, M. (2017). A predictionary of the humanities. Moscow: Novoe literaturnoe obozrenie.

Gordienko, O.V. (2017). Creatively oriented methodology as a factor in the development of professional thinking of the future teacher of Russian language. Moscow: MPGU.

Howe, N., \& Strauss W. (2008). Millennials Coming to College: Strategies for a New Generation on Campus (2nd ed.). Retrieved from http://citeseerx.ist.psu.edu/viewdoc/download?doi=10.1.1.472.8236\&rep=rep1\&type=pdf

Kuraev, A. (2000). Christian in the pagan world. Moscow: Russkiy pravoslavniy institute.

Kyazimov, K. G. (2016). The formation of an innovative educational environment in the regions and in the organizations of professional education. Professional Education, 9, 15-19.

Lubkov, A.V. (2019). Digitization of education: values and meanings. Moscow: RUDN.

McLuhan, M. (1994). Understanding media. The extensions of man. Cambridge: The MIT Press.

Popov, A. A., \& Ermakov, S. V. (2019). Open Education Didactics. Moscow: Nacionalniy knizniy centr.

Roskams, J. (2015). The developing brain: Implications for youth programs. Paper presented at the Kristin Anderson Moore Lecture Series, Bethesda.

Ushinskiy, K. D. (1974). Selected pedagogical works in 2 volumes. Moscow: MGPPU.

Verbitskiy, A. A. (2016). "Digital generation": Educational problems. Professional Education, 7, 10-13. 